\title{
RHOXF2 gene, a new candidate gene for spermatogenesis failure
}

Christophe Frainais ${ }^{1}$, Caroline Kannengiesser ${ }^{2}$, Martine Albert ${ }^{3,4}$, Denise Molina-Gomes ${ }^{4}$, Florence Boitrelle ${ }^{3,4}$, Marc Bailly ${ }^{4}$, Bernard Grandchamp ${ }^{2}$, Jacqueline Selva $a^{3,4}$ and François Vialard ${ }^{3,4^{*}}$

\begin{abstract}
Introduction: Genes involved in testicular differentiation, spermatogenesis, proliferation and apoptosis of germ cells have been shown to evolve rapidly and display rapid DNA changes. These genes are therefore good candidates for explaining impairments in spermatogenesis. Initial studies of some of these genes appear to confirm this hypothesis. The RHOXF2 candidate gene belongs to the RHOX family clustered in Xq24 and is specifically expressed in the testis. It contains four exons and codes for a 288 amino acid (aa) transcription factor. It has a high degree of homology (>99.9\%) with its paralogue RHOXF2B, which is also preferentially expressed in the testis.
\end{abstract}

Objectives: To sequence RHOXF2 and RHOXF2B in intracytoplasmic sperm injection (ICSI) patients and identify any single-nucleotide polymorphisms (SNPs) associated with impaired spermatogenesis.

Materials: A cohort of 327 patients in ICSI programmes at Poissy and Bichat hospitals. All patients gave their written, informed consent to participation. One hundred patients had unaffected spermatogenesis and 227 displayed impaired spermatogenesis.

Methods: The four exons in each of RHOXF2 and RHOXF2B were sequenced in 47 patients with oligospermia or non-obstructive azoospermia. Given that exons 2 and 3 were found to harbour most of the SNPs, only these two exons were sequenced in the remaining 280 subjects.

Results: Due to the extremely high degree of sequence identity between RHOXF2 and RHOXF2B, we were not able to distinguish between the sequences of these two genes. Although 9 SNPs were identified, there were no significant frequency differences between ICSI patients with normal vs. impaired spermatogenesis. Two insertions were identified: a 21-nucleotide insertion was retrieved in both groups and a guanine insertion (inducing a premature stop codon) only found in two patients with impaired spermatogenesis.

Conclusion/outlook: RHOXF2 is a good candidate for rapid evolution by positive selection. Analysis of the polymorphism frequency in exons 2 and 3 did not allow us to correlate the identified SNPs with male infertility. However, a single nucleotide insertion was identified only in men with impaired spermatogenesis. Further work will be needed to establish whether genetic changes in RHOXF2 can give rise to defects in spermatogenesis.

Keywords: RHOXF2, Positive selection pressure, Infertility, Gene cluster, Homoedomain

\footnotetext{
* Correspondence: fvialard@ chi-poissy-st-germain.fr

${ }^{3}$ EA 2493, University of Versailles Saint-Quentin, Versailles F-78035, France

${ }^{4}$ Department of Reproductive Biology, Cytogenetics, Gynecology and

Obstetrics, Poissy Saint Germain Hospital, Poissy F-78303, France

Full list of author information is available at the end of the article
} 


\section{Résumé}

Introduction: Les gènes impliqués dans la différenciation des testicules, la spermatogenèse, la prolifération et l'apoptose des cellules germinales ont été montrés comme ayant une évolution rapide de la séquence d'ADN. Ces gènes sont donc de bons candidats pour expliquer les déficiences de la spermatogenèse. Les premières études semblent confirmer cette hypothèse. Le gène RHOXF2, appartenant à la famille des gènes RHOX avec un cluster dans Xq24, est un bon candidat car spécifiquement exprimé dans les testicules. Ce gène a un degré élevé d'homologie (> 99,9\%), avec son paralogue RHOXF2B , qui est également exprimé préférentiellement dans les testicules.

Objectifs: Séquencer RHOXF2 chez des patients infertiles bénéficiant d'une injection intracytoplasmique de spermatozoïdes (ICSI) afin d'identifier des polymorphismes associés à une déficience de la spermatogenèse.

Matériels: Une cohorte de 327 patients inclus dans un programme d'ICSI. Tous les patients ont donné leur consentement écrit et éclairé à la participation de cette étude. Cent patients n'avaient pas d'altération de la spermatogenèse et 227 avaient une déficience.

Méthodes: Les quatre exons de RHOXF2 ont été séquencés chez 47 patients présentant une oligospermie ou une azoospermie non obstructive. Étant donné que les exons 2 et 3 ont été trouvés comme ayant le plus de SNPs, seuls ces deux exons ont été séquencés dans les 280 sujets restants.

Résultats: Bien que 9 SNPs aient été identifiés, il n'y avait pas de différence de fréquences significatives entre les patients ayant une altération, ou non de la spermatogenèse. Deux insertions ont été identifiées: une insertion de 21 nucléotides retrouvées dans les deux groupes et une insertion d'une guanine (induisant un codon stop prématuré) chez deux patients présentant une altération de la spermatogenèse.

Conclusion: RHOXF2 est un bon candidat pour une évolution rapide par sélection positive. L'analyse de la fréquence des polymorphismes dans les exons 2 et 3 ne nous permet pas actuellement de corréler les SNP identifiés avec l'infertilité masculine. Cependant, une insertion d'un seul nucléotide a été identifiée uniquement chez des hommes avec une déficience de la spermatogenèse. Des travaux complémentaires seront nécessaires pour déterminer l'impact du gène RHOXF2 sur la spermatogenèse.

Keywords: RHOXF2, Pression de selection positive, Infertilité, Cluster de gènes, Homéodomaine

\section{Introduction}

The study of genetic divergence between humans and chimpanzees [1] revealed the existence of certain groups of rapidly evolving genes subject to positive selection. This translates into a relatively high frequency of nucleotide sequence changes and then amino acid substitutions. More recently, studies of human single nucleotide polymorphisms (SNPs) have shown that some human genes have evolved in response to positive selection pressure [2]. This mechanism seems to preferentially affect genes involved in gametogenesis, apoptosis and immunity. Of these candidate genes, RHOXF2, USP-26, Spo-11 and PRM1 and $P R M 2$ are involved in different stages of spermatogenesis, $N R O B 1$ and $R E \alpha$ are involved in testicular differentiation, and HYAL3 and TSARG1 are involved in the proliferation/apoptosis of germ cells. Due to the presence of a large number of genes involved in the mechanisms of gametogenesis, it has been suggested that at least some of them have a role in infertility. Nielsen [1] hypothesized that mutations that increase cell proliferation and decrease germ cell apoptosis can sometimes be detrimental for the development of other parts of the body and may thus be subject to genomic conflict. This phenomenon might be partly responsible for the positive selection of these genes. Studies comparing infertile men with impaired spermatogenesis (oligospermia or azoospermic of secretory origin) with a control population of patients with normal spermatogenesis have already been undertaken. The preliminary results appear to confirm the involvement of genes such as USP26 [3], PRM1, PRM2 [4-6], TNP1, TNP2 [7], Spo11

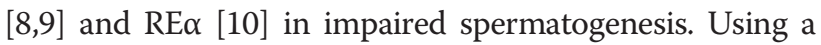
candidate gene approach, we chose to study the RHOXF2 gene (also known as PEPP-2 for Pem, Esx1, Psx1, PSx2). RHOXF2 is a member of the RHOX family of genes located in Xq24. It features a the Pem DNA homeobox sequence encoding a 60 amino acid (aa) homeodomain protein that interacts with DNA. The protein is expressed in Sertoli cells $[11,12]$ and is involved in germ cell development in mice [11-13]. The RHOX gene family forms a cluster on the $\mathrm{X}$ chromosome in humans (RHOXF1, RHOXF2 and RHOXF2B) (Figure 1) and in mice (comprising 12 genes). This family is characterized by two introns that are always located at the same point within the homeodomain. RHOXF2 has four exons and encodes a transcription factor that is specifically expressed in the testis. Although the transcription factor's role is not known in 


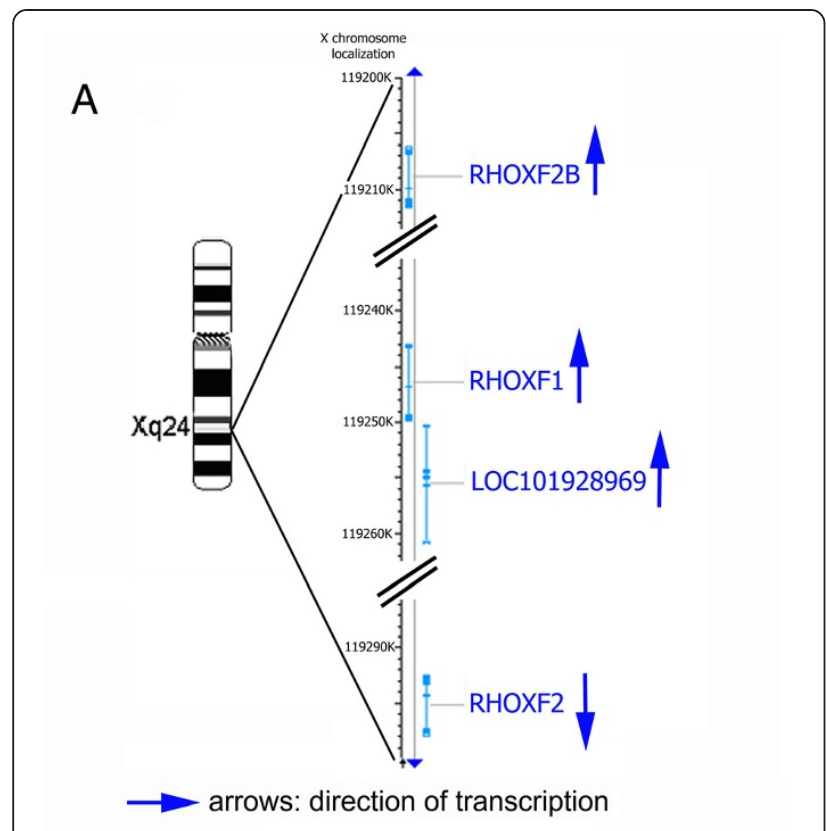

B

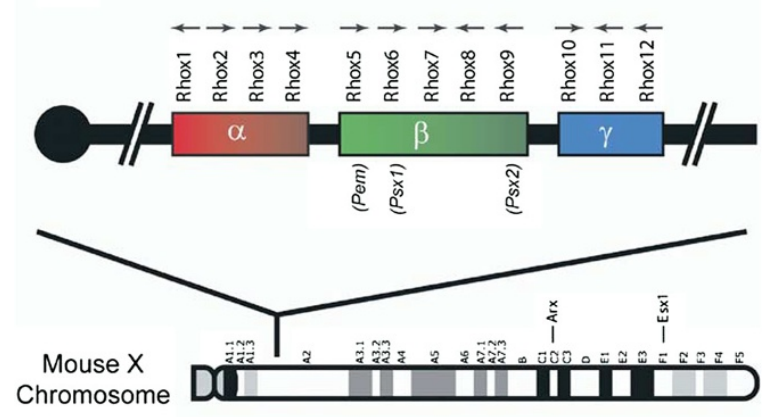

C

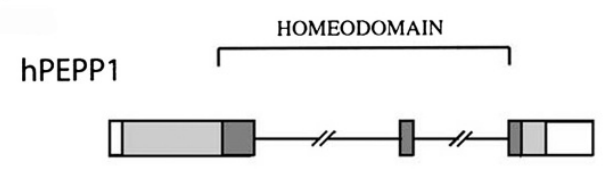

hPEPP2

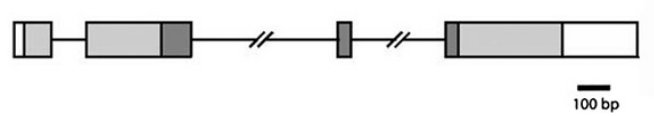

Figure 1 RHOX genes. A. Human RHOX cluster. B. Mouse RHOX cluster (from Mc Lean et al. [13]). C. Human RHOXF1 and RHOXF2 (from Wayne et al. [12]).

humans, the murine Rhox 5/Pem gene (an orthologue of RHOXF2) is involved in sperm maturation [13]. It encodes a 288 amino acids protein with a high glutamic acid Nterminal domain and a proline-rich domain in the $\mathrm{C}$ terminal [14]. When comparing the human and Pan troglodytes chimpanzee RHOXF2 sequences, 21 differences have been described: 3 in exon 1, 8 in exon 2, 2 in exon 3 and 7 in exon 4. In human exon 2, there is also a 21 bp (CAG CAGAAC CCC GTC ACC GCC) insertion at nucleotide 322. In humans, the RHOXF2 and RHOXF2B paralogues have a very high degree of sequence homology $(>99.9 \%)$ but has the opposite orientation on the X chromosome. The currently known differences between the two genes are an adenine-thymine substitution at codon 93 and a thymine-cytosine substitution at codon 131 [14]. To date, few polymorphisms have been described for this gene [14]. More recently, [15], a study of RHOXF2 copy number in primates showed that duplication only occurred in humans and four Old World monkey species (with at least 6 copies in chimpanzees). Furthermore, there was evidence of on-going selection for RHOXF2. Recently, it has been shown that the RHOXF2/2B genes are selectively expressed in the testis - primarily in germ cells in the adult testis but also in prespermatogonia in the human foetal testis. RHOXF2/2B mRNA expression increases in the second trimester during the development of the foetal testes (when gonocytes differentiate into prespermatogonia) [16]. The objective of the present study was to test for the involvement of RHOXF2 genes in male infertility of secretory origin. To this end, we implemented a twostep strategy. In order to confirm the presence of new sequence variants, we first sequenced the $R H O X F 2 / 2 B$ genes in a group of patients with impaired spermatogenesis. We then compared cases and controls in terms of the frequency of the newly identified SNPs.

\section{Material and methods}

Population (Table 1): We sequenced RHOXF2 in 327 primary infertility patients participating in in vitro fertilization (IVF) programmes at Poissy and Bichat hospitals. The patients were divided into two groups as a function of the alteration in spermatogenesis (Table 1). Group 1 comprised patients with normal sperm characteristics (according to the WHO criteria [17]; sperm count $>39 \times 10^{6} /$ ejaculate or $>15 \times 10^{6} / \mathrm{ml}$ ) participating in an intracytoplasmic sperm injection (ICSI) program for conventional IVF failures (Group 1a, $\mathrm{n}=73$ ) and patients with obstructive azoospermia and normal spermatogenesis (Group 1b, $\mathrm{n}=27$ ). All group $1 \mathrm{~b}$ patients had a normal testicular volume, urinary tract abnormalities (as confirmed by clinical and ultrasound examinations), alterations in at least one semen biochemistry parameter and normal testicular histology. Group 2 comprised patients with oligospermia (sperm count $<39 \times 10^{6} \%$ ejaculate or $<15 \times 10^{6} / \mathrm{ml}$ ) (group $2 \mathrm{a}, \mathrm{n}=168$ ) or nonobstructive azoospermia (Group $2 \mathrm{~b}, \mathrm{n}=59$ ). All azoospermic patients had altered testicular histology, normal semen markers, low testicular volume (volume $<10 \mathrm{ml}$ ) and no chronic pelvic inflammatory disease (i.e. a negative semen culture and fewer than $1 \times 10^{6}$ round cells per ejaculate).

Infertile patients had undergone extensive assessment, including family and personal medical histories, physical 
Table 1 Patients' testicular and hormonal parameters

\begin{tabular}{|c|c|c|c|c|}
\hline \multirow[t]{2}{*}{ Groups } & \multicolumn{2}{|c|}{ 1: Normal spermatogenesis } & \multicolumn{2}{|c|}{ 2: Altered spermatogenesis } \\
\hline & a: Control & b: Obstructive azoospermia & a: Oligospermia & b: Non obstructive azoospermia \\
\hline Patients number & 73 & 27 & 167 & 60 \\
\hline Semen Volume (ml) & $4.1^{*} \pm 1.7^{* *}$ & $2.8 \pm 2.2$ & $3.6 \pm 1.8$ & $3.5 \pm 1.4$ \\
\hline Sperm count (M/ml) & $68.8 \pm 61.7$ & / & $2.7 \pm 3.6$ & / \\
\hline Motility $(a+b)(\%)$ & $54.2 \pm 10.4$ & / & $22.9 \pm 16.4$ & / \\
\hline Normal form (\%) & $43.2 \pm 10.4$ & / & $11.9 \pm 11.3$ & / \\
\hline FSH (UI/l) & $5.0 \pm 3.9$ & $3.9 \pm 1.9$ & $11.9 \pm 8.5$ & $21.2 \pm 13.5$ \\
\hline $\mathrm{LH}(\mathrm{UI} / \mathrm{l})$ & $3.3 \pm 1.4$ & $3.2 \pm 1.4$ & $5.7 \pm 3.1$ & $7.5 \pm 4.7$ \\
\hline Total testosterone $(\mathrm{ng} / \mathrm{ml})$ & $4.8 \pm 2.3$ & $4.8 \pm 1.7$ & $4.5 \pm 1.8$ & $4.0 \pm 1.5$ \\
\hline Inhibine B (pg/ml) & $172.5 \pm 69.0$ & $158.4 \pm 79.0$ & $81.2 \pm 60.1$ & $33.3 \pm 47.3$ \\
\hline
\end{tabular}

*mean; ${ }^{* *}$ standard deviation.

and/or ultrasound examinations, karyotyping and Y deletion analysis. Testicular histology parameters and semen biochemical parameters (L-carnitine, fructose and citric acid) were analyzed in azoospermic patients. Sperm parameters were evaluated according to standard criteria (WHO, 1999). The hormone profile (FSH, LH, inhibin B and total testosterone) was determined in all groups of patients. All patients had a normal blood karyotype and no chromosome Y microdeletions. All participants gave their written, informed consent to participation in the study (which had been approved by an independent ethics committee CPP Ile de France XI) during pre-IVF genetic counselling.

The major exclusion criteria were as follows: age $>50$, vasectomy, endocrine disorders (hypogonadotropic hypogonadism), hormone therapy, toxic habits ( $>40$ cigarettes per day, alcohol abuse and/or drug abuse), immunosuppressive treatment, chemotherapy and/or radiotherapy, unilateral orchidectomy, abnormal karyotype, Y chromosome deletions and chronic genital tract infections.

In order to identify potential polymorphisms and mutations, we initially sequenced all four RHOXF2 exons in 47 patients with oligospermia or non-obstructive azoospermia (i.e. from groups $2 \mathrm{a}$ and $2 \mathrm{~b}$ ). We then sequenced exons 2 and 3 in the remaining 280 participants. All genetic variations were compared with the 1000 Genomes (http://browser.1000genomes.org/Homo_sapiens) and Exome Variant Server (EVS) (http://evs.gs.washington.edu/ EVS/) databases.

Genomic DNA was extracted from blood samples using the Wizard ${ }^{\circledR}$ GenomicDNA Purification kit (Promega, Southampton, UK).

\section{Primer design}

The primer pairs for each of the four exons were selected using Oligo software (Molecular Biology Insights, Inc. Cascade, CO, USA). The forward and reverse primer sequences consisted of 21 to 30 nucleotides and were selected 25-30 nucleotides upstream and downstream of the exons (with a minimum number of G/Cs, in order to prevent dimer formation) (Table 2).

\section{DNA amplification}

PCRs were performed on $1 \mu$ l of native DNA with Taq Gold ${ }^{\bullet}, 3 \mu \mathrm{l} 25 \mathrm{mM} \mathrm{MgCl} 2$, and $1 \mu \mathrm{l} 5 \mathrm{mM}$ dNTP. A total of 35 cycles were performed (denaturation at $96^{\circ} \mathrm{C}$ for $30 \mathrm{~s}$; hybridisation at $60^{\circ} \mathrm{C}$ for $30 \mathrm{~s}$ (exons 1 and 2) or $57^{\circ} \mathrm{C}$ for $30 \mathrm{~s}$ (exons 3 and 4); elongation at $72^{\circ} \mathrm{C}$ for $60 \mathrm{~s}$ ). The PCR fragments were then purified enzymatically with ExoSAP (USB, Cleveland, Ohio, USA).

\section{DNA sequencing}

DNA was sequenced using $1 \mu \mathrm{l}$ Big Dye Terminator on an Eppendorf thermocycler with the following program: hot start: $96^{\circ} \mathrm{C}$ for $5 \mathrm{~min} ; 25$ cycles (denaturation at $96^{\circ} \mathrm{C}$ for $30 \mathrm{~s}$, hybridization at $50^{\circ} \mathrm{C}$ for $15 \mathrm{~s}$, elongation at $60^{\circ} \mathrm{C}$ for $4 \mathrm{~min}$ ); final elongation: $60^{\circ} \mathrm{C}, 10 \mathrm{~min}$. After purification on a Sephadex G50 plate Millipore column, raw sequences were analyzed and interpreted with Seqscape ${ }^{\bullet}$ software (Applied Biosystems, Life Biotechnologies, NY, USA).

\section{Statistical analysis}

Intergroup comparisons of polymorphism and haplotype frequencies were performed with Fisher's exact test and

\section{Table 2 Primers sequences}

\begin{tabular}{ccc}
\hline Exon & & Primer \\
\hline 1 & Forward & AGACACCAGAAGAACGTTGCAGGC \\
& Reverse & TGAGAGCAGTGGTAGTGCAGGGGT \\
2 & Forward & CATAGCCCCACTACAGAACCCACTAGG \\
& Reverse & ACTGGATGATACCCCTGCACTACCACT \\
3 & Forward & TGAGGCTCAGCTGGGTGTACAGAAC \\
& Reverse & TTGCCTATACATGAAAAAGGCCACAA \\
4 & Forward & CACTAGGGGAAAGGTGGGTGGTA \\
& Reverse & TACAAGTGCCCTAAAAATGGGTCAATGAT \\
\hline
\end{tabular}


the chi-squared test. The threshold for statistical significance was set to $\mathrm{p}<0.05$. All analyses were performed with Statview software (SAS Institute Inc., Cary, NC, USA).

\section{Results (Table $\mathbf{3}$ )}

First, all four RHOXF2 exons were sequenced in 47 patients with oligospermia or non-obstructive azoospermia. The sequences corresponded to RHOXF2. In view of the high degree of sequence homology ( $>99.9 \%)$, a pseudobiallelic nomenclature was adopted for the SNPs' genotype. Five previously described heterozygous SNPs [14] were identified: 3 on exon 2, one on exon 3 and one on exon 4. These SNPs were also present in the $1000 \mathrm{Ge}$ nomes and EVS databases. A previously described frameshift variant in exon 2 (a guanine insertion leading to a premature stop codon (TGA) of the cDNA (c.381dupG).p. (L128Afs*34)) was also identified. Given that we did not find any new SNPs in exons 1 and 4, we decided to only study exons 2 and 3 in the remaining 280 patients. The overall study population therefore comprised 100 patients from group I and 227 patients from group II. We identified five heterozygous SNPs (all located in exon 2) in our population. Three had been reported previously and two had not. One of the latter was a 21-nucleotide duplication (GAG AAG AAA AAG ATG GCG GCGGCC) from nucleotide 246 onwards; this leads to a 7 aa protein duplication (QKKKMAA) at aa 82 and thus a 295 aa protein). This duplication (official nomenclature: c.225_245dup,p. (Glu76_Gly82dup)) was found in one patient from group I and three patients from group II. A c.381dupG was found in one patients with impaired spermatogenesis. Overall, four SNPs were synonymous and five were non-synonymous. Furthermore, two insertions (one of which led to a premature stop codon) were identified only in patients with spermatogenesis failure. There were no intergroup differences in SNP frequency (Table 3) and no haplotype differences were observed when combining the three most frequent SNPs (p.D93N, R151H and p.L176F). Three patients were homozygous for D93N and one was homozygous for R151H.

Sperm characteristics were for the two oligospermic patients with the c.381dupG as follow : Patient 1: sperm count: $2.20 \times 10^{6} / \mathrm{ml}$, motility: $38 \%$, typical form: $0 \%$; Patient 2: sperm count: $4 / \mathrm{ml}$, .motility and typical form not performed.

Considering all subgroups separately (Additional file 1: Table S1), the only significant frequency difference was observed for p.D93N (the most frequent SNP, found in $74.2 \%$ of the study population) comparing azoospermic (73.8\%) and oligospermic patients $(88.1 \%)$ with spermatogenesis failure $(\mathrm{p}=0.0288)$.

\section{Discussion}

Genetic divergence between Homo sapiens and the chimpanzee may result from positive selection pressure (notably on genes involved in immunity, gametogenesis and apoptosis) [1,2]. The positive selection pressure on male gametogenesis is higher in humans than in the chimpanzee [18]. Rapid evolution of these genes leads to changes in one or more nucleotides, which in turn can impair the function of the corresponding protein and, in some cases, cause infertility. In humans, the $\mathrm{X}$ and $\mathrm{Y}$ chromosomes are particularly exposed to this selection pressure because of the absence of $\mathrm{Y}$ homologous recombination during meiosis and low recombination

Table 3 Exons 2 and 3 SNPs frequencies

\begin{tabular}{|c|c|c|c|c|c|c|}
\hline $\begin{array}{l}\text { SNP and DNA change } \\
\text { (Included in the homeodomain) }\end{array}$ & & Previously described & $\begin{array}{c}\text { Variant type genetic } \\
\text { Variation at protein level }\end{array}$ & $\begin{array}{c}\text { Group } 1 \\
(n=100) \\
n(\%)\end{array}$ & $\begin{array}{c}\text { Group } 2 \\
(n=227) \\
n(\%)\end{array}$ & $p($ I vs II $)=$ \\
\hline c. $202 \mathrm{G}>\mathrm{A}$ & & rs148604152 & Missense p.G68R & $1(1.0)$ & $1(0.4)$ & 0.5188 \\
\hline c.225_245dup, & & No & p.Glu76_Gly82dup & $1(1.0)$ & $3(1.3)$ & 1 \\
\hline c. $267 \mathrm{~A}>\mathrm{G}$ & & rs149340601 & Synonymous p.L89= & $2(2.0)$ & 0 & 0.0929 \\
\hline \multirow[t]{2}{*}{ c. $277 G>A$} & all & rs146311958 & Missense p.D93N & $75(75.0)$ & $176(77.5)$ & 0.6703 \\
\hline & Homozygote & & & $1(1.0)$ & $2(0.9)$ & 1 \\
\hline c.381dupG & & Yes no rs & Frameshift p.L128Afs*34 & 0 & $2(0.9)$ & 0.8617 \\
\hline c.381C > T & & No & Synonymous p.G127= & 0 & $1(0.4)$ & 1 \\
\hline c.396C > T & & rs199940228 & Synonymous p.A133= & 0 & $1(0.4)$ & 1 \\
\hline c. $411 C>T$ & & rs142963365 & Synonymous p.N137= & 0 & $1(0.4)$ & 1 \\
\hline$c .451 C>T$ & & no & Missense p.R151C & 0 & $2(0.9)$ & 1 \\
\hline \multirow[t]{2}{*}{ c. $452 \mathrm{G}>\mathrm{A}$} & all & rs142899626 & Missense p.R151H & $40(40.0)$ & $98(43.2)$ & 0.6281 \\
\hline & Homozygote & & & 0 & $1(0.4)$ & 1 \\
\hline c. $526 \mathrm{C}>\mathrm{T}$ & & rs199871532 & Missense p.L176F & $10(10.0)$ & $17(7.5)$ & 0.5136 \\
\hline
\end{tabular}


rates $(50 \%)$ for the $\mathrm{X}$ chromosome. It has also been shown that male infertility can be related to Y chromosome defects [19-23]. One can therefore hypothesize that male infertility can be caused by polymorphisms in $\mathrm{X}$ chromosome genes involved in spermatogenesis. $\mathrm{Mu}-$ tations in the USP26 gene in Xq28 (also considered to be subject to positive selection pressure) were found in $7 \%$ of a series of patients with Sertoli cell-only syndrome [24]. The fact that other X chromosome polymorphisms (both SNPs [25] and copy number variations [26]) have been recently reported strengthens the hypothesis whereby they have an impact on spermatogenesis. The RHOX family gene is located in Xq24 and codes for transcription factors that are only expressed in the testes. Mice have 12 RHOX orthologues, which are also organised in a cluster $[12,13]$. Some of these genes are only partially duplicated $[27,28]$. Of these, Rhox 5 is expressed in Sertoli cells and appears to have an important role in spermatogenesis. Impaired expression leads to azoo-teratospermia and increased apoptosis of germ cells. Humans RHOXF2 presents a high degree of sequence homology (63.8\%) with the mouse Rhox 5 gene [12]. Few RHOXF2 polymorphisms have been identified and there are no data on their frequency. In humans, the RHOXF2 and RHOXF2B paralogues have a very high degree of sequence homology (>99.9\%). RHOXF2B is located less than $100 \mathrm{~kb}$ away from RHOXF2 but has the opposite orientation. The human gene duplication is thought to have occurred very recently [14]. Due to the very high degree of homology (99.9\%), there are no data on the differential expression of these two paralogues. A recent study of sequence and copy number variations of RHOXF2 in humans and a nonhuman primates showed a parallel gene duplications/ losses in multiple primate lineages [15]. Eleven nonhuman primate species have only one RHOXF2 copy, two copies are present in humans and four Old World species of monkey and at least six copies are present in chimpanzees. The gene duplication in primates was probably mediated by non-allelic recombination via flanking endogenous retroviral sequences [15]. Furthermore, an analysis of eight non-synonymous variant sites in humans has suggested that the gene selection process is on-going. Furthermore, it was recently reported that $R H O X F 2 B$ is selectively expressed in male germ cells [16]. These various datasets support the hypothesis whereby RHOXF2 variants may be present in patients with impaired spermatogenesis. Our two-step strategy (based on the preliminary identification of new variants in a small group of patients with impaired spermatogenesis and then extension of the analysis to control patients) enabled us to identify (i) new synonymous and missense variants and (ii) two frame-shift variants (one of which was associated with a premature stop codon). However, patients with and without impaired spermatogenesis did not differ in terms of the frequency of these polymorphisms. We established haplotypes on the basis of the three most frequent polymorphisms but again did not observe any differences in frequency between the two groups of patients. These findings suggest that there is no correlation between the frequency of RHOXF2 polymorphisms and impaired spermatogenesis. However, this result is preliminary because our study only covered RHOXF2's coding sequences. It would be interesting to study the promoter regions in patients with impaired spermatogenesis. The RHOXF2 promoter has a high degree of homology with that of the mouse Rhox 5 gene [12], which contains an androgen binding site. The presence of polymorphisms in this region could therefore modulate RHOXF2 transcription and reduce translation. In the mouse, low Rhox 5 expression was shown to have a harmful effect on spermatogenesis [13]. Furthermore, we did not study exon 4, which carries a polymorphism that is defined as harmful by the PANTHER classification system (http://www.pantherdb.org). We identified two rare duplications in our patients with impaired spermatogenesis. The first duplication is a guanine insertion that shifts the reading frame, induces a premature stop codon and thus produces a truncated protein. This duplication was found in two patients with spermatogenesis failure and none of the control patients. The EVS database lists this duplication for only one individual, the fertility of which is not stated. Given that Rhox gene mutation alter testicular function in rodents [27], this variant may indeed be pathogenic. The second duplication is located in exon 2 . This is a duplication of a 21-bp fragment from base 165, resulting in the insertion of a 7 aa polypeptide (but no change in the homeodomain). This mutation was identified in three patients with impaired spermatogenesis and in one control patient.

Except for the frameshift mutation p.L128Afs*34 which disrupts the homeodomain (from amino acid 134 to 193), the others SNPs do not exhibit a specific phenotype. This may be due to several aspects. Firstly, seven of the 11 reported SNPs were outside the homoeodomain. Secondly, one of the remaining four SNPs is synonymous. For 2 of the others, the substituted amino acid is quite similar to the native amino acid and thus does not induce a great change in homeodomain's conformation (the basic amino acid arginine and histidine for $\mathrm{p} \cdot \mathrm{R} 151 \mathrm{H}$ and the non-polar leucine and phenylalanine amino acids for p.L176F). The most interesting variation is probably p.R151C, in which arginine is replaced by the dissimilar cysteine. A change in the homeodomain's interaction with DNA cannot therefore be ruled out. When compared with the two previously mentioned SNPs, p.R151C was only observed in the group of patients with spermatogenesis failure. However, the very low frequency explains the absence of a statistically significant difference (as was is also the case for the frameshift mutation p.L128Afs*34). Thirdly, the amino 
acid positions 151 and 176 were not conserved across orthologues [12]. Hence, these various points may explain why negative results were observed in our series and, in particular, why the RHOXF2 SNPs did not appear to predispose their bearers to infertility.Due to technical limitations and the very high degree of homology between RHOXF2 and RHOXF2B, we could not distinguish between RHOXF2 or RHOXF2B polymorphisms. It is not yet known whether the two paralogues have distinct functions or complement each other perfectly. It is therefore impossible to determine the relative impact of the different polymorphisms or duplications on spermatogenesis. In order to confirm our present results, it would be interesting to sequence exon 2 in a larger cohort of patients and controls. An analysis of RHOXF2 and RHOXF2B expression patterns would also be very interesting but would require us to be distinguish between the two paralogues.

\section{Conclusion}

Mutations in the RHOXF2 and RHOXF2B genes (which encode homeodomain proteins exclusively expressed in the testis) might explain some cases of male infertility. Our study confirmed the presence of the polymorphisms identified by Wayne [14] and a number of new polymorphisms. A truncating mutation (caused by insertion of a nucleotide) was encountered only in patients with impaired spermatogenesis. Although several polymorphisms were identified in RHOXF2 and RHOXF2B (suggesting recent positive selection pressure), there were no significant difference between patients with impaired spermatogenesis and control patients in terms of the polymorphism frequencies. It would nevertheless be interesting to (i) continue this analysis of RHOXF2 and RHOXF2B in a larger population, (ii) sequence exon 4 and the promoter sequence and (ii) study other testis-active genes located on chromosome X, (such as PEPP-1 (OTEX) [14,29], ESX1-R [30], ESX-1 L [31,32], TGIFL-X [33]) or genes that have been subjected to positive selection pressure. If possible, specific analysis of RHOXF2 and RHOXF2B expression should tell us whether both genes are expressed exclusively in the testis and which of the two paralogues is required for spermatogenesis.

\section{Additional file}

Additional file 1: Table S1. Exons 2 and 3 SNPs frequencies in all subgroups.

\section{Abbreviations}

aa: Amino acid; SNPs: Single-nucleotide polymorphisms;

ICSI: Intracytoplasmic sperm injection; IVF: In vitro fertilization.

\section{Competing interests}

The authors declare that they have no competing interests.
Authors' contribution

CF carried out the molecular genetic studies, participated in the sequence alignment and drafted the manuscript. CK participated to the sequence alignment and drafted the manuscript. MA participated to patients inclusion and results discussion. DMG participated to patients inclusion and results discussion. FB drafted the manuscript. MB participated to patients inclusion and results discussion. BG lab director and participated in the sequence alignment. JS lab director and design the study. FV Design the study and drafted the manuscript. All authors read and approved the final manuscript.

\section{Author details}

${ }^{1}$ Laboratoire Clement, Le Blanc Mesnil F-93110, France. ${ }^{2}$ Department of Genetics, Hôpital Bichat, Paris F-75018, France. ${ }^{3}$ EA 2493, University of Versailles Saint-Quentin, Versailles F-78035, France. ${ }^{4}$ Department of Reproductive Biology, Cytogenetics, Gynecology and Obstetrics, Poissy Saint Germain Hospital, Poissy F-78303, France.

Received: 4 October 2013 Accepted: 27 January 2014

Published: 10 February 2014

\section{References}

1. Nielsen R, Bustamante C, Clark AG, Glanowski S, Sackton TB, Hubisz MJ, Fledel-Alon A, Tanenbaum DM, Civello D, White TJ, et al: A scan for positively selected genes in the genomes of humans and chimpanzees. PLoS Biol 2005, 3:e170.

2. Voight BF, Kudaravalli S, Wen $X$, Pritchard JK: A map of recent positive selection in the human genome. PLoS Biol 2006, 4:e72.

3. Paduch DA, Mielnik A, Schlegel PN: Novel mutations in testis-specific ubiquitin protease 26 gene may cause male infertility and hypogonadism. Reprod Biomed Online 2005, 10:747-754.

4. Iguchi N, Yang S, Lamb DJ, Hecht NB: An SNP in protamine 1: a possible genetic cause of male infertility? J Med Genet 2006, 43:382-384.

5. Oliva R: Protamines and male infertility. Hum Reprod Update 2006, 12:417-435.

6. Tanaka H, Miyagawa Y, Tsujimura A, Matsumiya K, Okuyama A, Nishimune Y: Single nucleotide polymorphisms in the protamine-1 and -2 genes of fertile and infertile human male populations. Mol Hum Reprod 2003, 9:69-73.

7. Miyagawa Y, Nishimura H, Tsujimura A, Matsuoka Y, Matsumiya K, Okuyama A, Nishimune $Y$, Tanaka $H$ : Single-nucleotide polymorphisms and mutation analyses of the TNP1 and TNP2 genes of fertile and infertile human male populations. J Androl 2005, 26:779-786.

8. Christensen GL, Ivanov IP, Atkins JF, Mielnik A, Schlegel PN, Carrell DT: Screening the SPO11 and EIF5A2 genes in a population of infertile men. Fertil Steril 2005, 84:758-760.

9. Mori T, Kurahashi H, Shinka T, Nakahori Y, Taniguchi M, Toda T, Iwamoto T: Candidate genes for male factor infertility-validation. Fertil Steril 2006, 86:1553-1554. author reply 1554.

10. Galan JJ, Guarducci E, Nuti F, Gonzalez A, Ruiz M, Ruiz A, Krausz C: Molecular analysis of estrogen receptor alpha gene AGATA haplotype and SNP12 in European populations: potential protective effect for cryptorchidism and lack of association with male infertility. Hum Reprod 2007, 22:444-449.

11. Rao MK, Wayne CM, Meistrich ML, Wilkinson MF: Pem homeobox gene promoter sequences that direct transcription in a Sertoli cell-specific, stage-specific, and androgen-dependent manner in the testis in vivo. Mol Endocrinol 2003, 17:223-233.

12. Wayne CM, Sutton K, Wilkinson MF: Expression of the pem homeobox gene in Sertoli cells increases the frequency of adjacent germ cells with deoxyribonucleic acid strand breaks. Endocrinology 2002, 143:4875-4885.

13. Maclean JA 2nd, Chen MA, Wayne CM, Bruce SR, Rao M, Meistrich ML, Macleod C, Wilkinson MF: Rhox: a new homeobox gene cluster. Cell 2005, 120:369-382.

14. Wayne CM, MacLean JA, Cornwall G, Wilkinson MF: Two novel human X-linked homeobox genes, hPEPP1 and hPEPP2, selectively expressed in the testis. Gene 2002, 301:1-11.

15. Niu AL, Wang YQ, Zhang H, Liao CH, Wang JK, Zhang R, Che J, Su B: Rapid evolution and copy number variation of primate RHOXF2, an X-linked homeobox gene involved in male reproduction and possibly brain function. BMC Evol Biol 2011, 11:298.

16. Song HW, Anderson RA, Bayne RA, Gromoll J, Shimasaki S, Chang RJ, Parast MM, Laurent LC, de Rooij DG, Hsieh TC, Wilkinson MF: The RHOX 
homeobox gene cluster is selectively expressed in human oocytes and male germ cells. Hum Reprod 2013, 28:1635-1646.

17. WHO: WHO laboratory manual for the examination and processing of human semen. Fifththth edition. World Heath Organisation; 2010.

18. Arbiza L, Dopazo J, Dopazo H: Positive selection, relaxation, and acceleration in the evolution of the human and chimp genome. PLoS Comput Biol 2006, 2:e38.

19. Delobel B, Djlelati R, Gabriel-Robez O, Croquette MF, Rousseaux-Prevost R, Rousseaux J, Rigot JM, Rumpler Y: Y-autosome translocation and infertility: usefulness of molecular, cytogenetic and meiotic studies. Hum Genet 1998, 102:98-102.

20. Krausz C, Siffroi J, Souleyreau-Therville N, Bourgeron T, McElreavey K, Fellous $\mathrm{M}$ : [Genetic control of spermatogenesis: $Y$ chromosome and male infertility]. Ann Biol Clin (Paris) 1999, 57:309-317.

21. Stuppia L, Calabrese G, Franchi PG, Mingarelli R, Morizio E, Sabatino G, Palka G: Molecular studies in three patients with isodicentric $Y$ chromosome. Hum Genet 1996, 98:691-695.

22. Yoshida A, Nakahori Y, Kuroki Y, Motoyama M, Araki Y, Miura K, Shirai M: Dicentric Y chromosome in an azoospermic male. Mol Hum Reprod 1997, 3:709-712.

23. Vogt PH: Azoospermia factor (AZF) in Yq11: towards a molecular understanding of its function for human male fertility and spermatogenesis. Reprod Biomed Online 2005, 10:81-93.

24. Stouffs K, Lissens W, Tournaye H, Van Steirteghem A, Liebaers I: Possible role of USP26 in patients with severely impaired spermatogenesis. Eur J Hum Genet 2005, 13:336-340.

25. Okuda H, Tsujimura A, Irie S, Yamamoto K, Fukuhara S, Matsuoka Y, Takao T, Miyagawa $\mathrm{Y}$, Nonomura N, Wada M, Tanaka H: A single nucleotide polymorphism within the novel sex-linked testis-specific retrotransposed PGAM4 gene influences human male fertility. PLoS One 2012, 7(5):e35195.

26. Krausz C, Giachini C, Lo Giacco D, Daguin F, Chianese C, Ars E, Ruiz-Castane E, Forti G, Rossi E: High resolution X chromosome-specific array-CGH detects new CNVs in infertile males. PLoS One 2012, 7(10):e44887.

27. MacLean JA 2nd, Lorenzetti D, Hu Z, Salerno WJ, Miller J, Wilkinson MF: Rhox homeobox gene cluster: recent duplication of three family members. Genesis 2006, 44:122-129.

28. Wang $X$, Zhang J: Remarkable expansions of an X-linked reproductive homeobox gene cluster in rodent evolution. Genomics 2006, 88:34-43.

29. Geserick C, Weiss B, Schleuning WD, Haendler B: OTEX, an androgenregulated human member of the paired-like class of homeobox genes. Biochem J 2002, 366:367-375.

30. Branford WW, Zhao GQ, Valerius MT, Weinstein M, Birkenmeier EH, Rowe LB, Potter SS: Spx1, a novel X-linked homeobox gene expressed during spermatogenesis. Mech Dev 1997, 65:87-98.

31. Fohn LE, Behringer RR: ESX1L, a novel $X$ chromosome-linked human homeobox gene expressed in the placenta and testis. Genomics 2001, 74:105-108

32. Wang $X$, Zhang J: Rapid evolution of primate ESX1, an X-linked placentaand testis-expressed homeobox gene. Hum Mol Genet 2007, 16:2053-2060

33. Wang $X$, Zhang J: Rapid evolution of mammalian X-linked testishomeobox genes. Genetics 2004, 167:879-888.

doi:10.1186/2051-4190-24-3

Cite this article as: Frainais et al:: RHOXF2 gene, a new candidate gene for spermatogenesis failure. Basic and Clinical Andrology 2014 24:3.

\section{Submit your next manuscript to BioMed Central and take full advantage of:}

- Convenient online submission

- Thorough peer review

- No space constraints or color figure charges

- Immediate publication on acceptance

- Inclusion in PubMed, CAS, Scopus and Google Scholar

- Research which is freely available for redistribution 